\title{
TESTING EMA INDICATOR FOR THE CURRENCY PAIR EUR / USD
}

\author{
Andrea KOLKOVÁ ${ }^{1}$ \\ College of Entrepreneurship and Law, Prague, Czech Republic
}

\begin{abstract}
ABSTRAKT
The aim of this paper is to verify the effectiveness of EMA indicator according to selected time intervals. The underlying assumption is that, on longer timescales EMA is profitable and provides more relevant signals. The second objective of this paper is to test the signals of indicators in different months. It is believed that in September and January the number of trading signals on this indicator will increase. Testing will be done on the five-minute time frame. The test will be subjected to 65,000 rate values of the EUR / USD currency pair. Effectiveness of the analysis will be evaluated on the basis of digital (binary) option. Business strategy is based on EMA crossover indicator of current exchange rate. By the contribution there were confirmed hypotheses about more profitable signals when selecting a greater timeframe breadth of moving average. There was also confirmed an increased amount of signals in September, but not in January.
\end{abstract}

\section{KEY WORDS}

Digital option, technical analysis, forex, exponencial moving average

\section{JEL CLASSIFICATION}

CODE G150, G170

\section{INTRODUCTION}

Technical analysis offers a multitude of options to respond to the changing situation on the markets with currency pairs. In their survey Taylor and Allen (1992) found that on the UK market at least 90\% respondents use technical analysis in making decisions about their portfolios. Camphbell (1997, p. 27) even considers the possibility of predicting financial asset prices as the main issue of financial econometrics. In a study of Oberlechner (2001) can also be obtained the use of technical analysis in comparison with the fundamental one. Obelechner (2001) focused only on trading and even divided the traders according to time horizon of trading. According to the logic technical analysis is more widely used by intraday traders, $65.3 \%$, while traders holding period of currency more than 1 year from $67.9 \%$ they tend to focus on fundamental analysis.

\footnotetext{
${ }^{1}$ Correspondence concerning this article should be addressed to Andrea Kolková, Vysoká škola podnikání a práva, a.s., unit: Vltavská 585/14, 15000 Praha 5 - Smíchov, head office: Michálkovická 181/1810, 710 00Ostrava - Slezská Ostrava, email: andrea.kolkova@vspp.cz
} 
The aim of this paper is to verify the effectiveness of EMA indicator according to selected time intervals. The underlying assumption is that, on longer timescales EMA is profitable and provides more relevant signals. The second objective is to test the signals of indicators in different months. It is believed that in September and January the number of trading signals on this indicator will increase.

\section{THEORETICAL BACKGROUND}

Technical analysis predicts future movement of rates based on the analysis of past prices with the use of qualitative methods such as graphical analysis as well as quantitative methods, such as moving average, exponential moving average, or using a combination of both. In accordance with the basic definition of Murphy (1999, p. 3), basic prerequisites of technical analysis are market prices that reflect all events, courses changing trends and historical prices tending to be repeated.

Technical analysis tries to predict the future development of prices on the base of analysis of past development (Murphy, 1999). For this purpose multiple methods can be used. The basis is always mathematical statistics (Kaufman, 2013). Possibilities of technical analysis should be divided into two groups, namely technical indicators and price action.

Systems based on the price action are known even in the 18th century, when the Japanese on their trades with rice applied first candle charts. Today they are published slightly less than the technical indicators, for example, K. H. Lee, G. S. Jo (1999), and are the subject of research rather on the base of programming, such as 'Izumi at all' (2006).

There are a number of technical indicators. Some are traditional and have been known for decades. Already in 1988 Colby issued encyclopedia of technical market indicators (Colby, 1988). More than three decades ago George Lane published his Lane's stochastic oscillator (Lane, 1984), or even in 70s the Relative Strength (RS) was developed by Wilder (1978). In the 80s-90s of 20th century for instance John Bollinger published Bollinger Bands indicator (Bollinger, 1992) which belongs to the group of channel systems that were already described by Kaufman (1987) and by this the list of indicators does not end.

Of more recent for example Chaikin oscillator is known (Achelis, 2001), and now widely used indicator MACD staged by Appel (2005). In 2007 (Cheung \& Kaymak, 2007) the concept of combining technical indicators and fuzzy logic was introduced. Abbasi and Abouec took advantage of the system derived from neuro-fuzzy logic (Abbasi, Abouec, 2008). In 2009 Chavarnakul \& Enke (2009) developed a hybrid model of stock trading using neuro-fuzzy concept called Genetic Algorithm (NF-GA). In 2015, the technical indicators (MACD in particular, and less well-known indicator Gann-Hilo) and fuzzy logic was used again (Chourmouziadis and Chatzoglou, 2015). Currently, there have always been new indicators constructed, such as Rubell at all (2016) based on both the fuzzy modeling, and a combination of statistical and mathematical indicators. The current ones are then subjected to various tests (da Costa, 2015).

Technical analysis can be applied to stock markets, commodity and currency. It can also be applied both to the shares directly, and to CFD and also to the derivative products of various kinds (options, futures, swaps). For example, the options still offer further options. One of them is a combination of options forming a variety of option strategies (Kolková, 2006). Others are a variety of exotic options, such as digital or binary, which were discussed for example by Rick Thachuk (2010), Jaworsky (2006), Jurník (2013) or Cánfas (2013). Regarding the use of technical analysis on these new financial products has been still little published. Alternatively, if so the attention is directed 
almost exclusively to the pricing of options such as Hong joong y and Kyoung-sook Moonz (2011), Zmeskal (2010), Thavaneswarana at all (2013) and Miyake (2016).

Foreign exchange rate (hereinafter referred to as forex) is the largest financial market in the world with a daily transaction volume exceeding 5 trillion dollars. It is a decentralized market, and therefore, unlike other assets the currencies can be traded 24 hours a day.

The risk is a permanent element in any investment activity, and therefore also on the forex market. Technical analysis according to Hada and Adamuta (2015) plays a significant role in the prevention of risks and is a key point for hedging risk in transactions with currency pairs. Since Forex trades are particularly high-risk, moreover, in conjunction with digital options, it is also advisable to use technical analysis for predicting future changes.

\section{RESEARCH METHODS}

Implementation of technical analysis in a particular market is based on thorough preparation of trading system. This can be described according to Costa (2015) as a set of rules that define conditions for the commencement or termination of trading. In this paper we will set up a trading system based on technical indicator EMA.

\subsection{Moving Averages}

Moving averages quantify the average value of the data in the breadth of its timeframe. For example, 7-day moving average is an average value in the last week, 14- days in the last two weeks. After combining of moving averages of all days, we can make a curve of moving average. The platforms enabling trades on the forex in most cases include the ability to represent moving averages automatically. Therefore traders are a very used tool, but without knowledge of their principles, however, they are worthless.

Exponential Moving Average (EMA hereinafter) is considered a better tool than the simple moving average (Elder, 2006), because it gives more weight to current data and corresponds to changes in prices faster than the simple one. It can be expressed as,

$E M A=P_{1} \cdot K+E M A_{0} \cdot(1-K)$, where

$$
K=\frac{2}{N+1},
$$

where $\mathrm{N}$ is the number of days to quantify the EMA,

$P_{1} \quad$ Is today's course and

$E M A_{0}$ Is yesterday's value of EMA.

In this paper, we applied again trading system based on EMA crossing with the current exchange rate, when crossing above is the signal to sell and an opposite crossing means the purchase. There is used 9-day, 10-day, 12-day and 26-day EMA.

\subsection{Methodology for evaluating the performance of the trading system}

For analysis there were used the courses of EUR/USD currency pair. Data acquisition program Metatrader 4 was used and the data with a five minute timeframe were subjected to the analysis. For a five-minute data there were analyzed 65,000 values of courses in the period from 03/06/2015 to $19 / 04 / / 2016$. These data were drawn from the program Metatrader 4 that downloads offered by 
most brokers. Through all broker (for example markets.com, cixmarkets, XTB, admiralmarkets and so one) then this program can draw data.

According to the trading system as defined in chapter 3.1, there were searched trading signals both to buy and to sell. Digital options with triple expiration were applied to these signals with the following logic: digital options up to the signals to purchase and digital options down to the signals for sale. In the current period digital options have $85.01 \%$ rate of return (for example, a broker XTB on the Basic Account). Based on this measure the total profits of the trading system are then calculated. All calculations are performed in Excel.

\section{RESULTS}

In Table 1 there are presented the results of the trading system for EUR/USD back-testing and then applied using a digital option.

Table $1 \quad$ Testing of EMA According to Time Frame

\begin{tabular}{|l|l|l|l|l|}
\hline Indicator & $\begin{array}{c}\text { Total Number } \\
\text { of Signals }\end{array}$ & $\begin{array}{c}\text { Number of } \\
\text { Signals } \\
\text { Generating } \\
\text { the Profit }\end{array}$ & $\begin{array}{c}\text { Percentage of } \\
\text { Profitable } \\
\text { Signals }\end{array}$ & $\begin{array}{c}\text { Profit } \\
\text { Using } \\
\text { Digital } \\
\text { Options }\end{array}$ \\
\hline EMA 9 & 13951 & 10771 & $77,21 \%$ & $15,63 \%$ \\
\hline EMA 10 & 13223 & 10272 & $77,68 \%$ & $16,04 \%$ \\
\hline EMA 12 & 12079 & 9456 & $78,28 \%$ & $16,55 \%$ \\
\hline EMA 26 & 8123 & 6418 & $79,01 \%$ & $17,17 \%$ \\
\hline
\end{tabular}

(Source: Author)

The table clearly shows that the choice of a higher timeframe leads to increased number of profitable trades and also to increased overall profits. Although it is a difference in tenths of percentage points a default assumption can be considered relevant.

Furthermore, the indicator EMA was tested in different months. It was confirmed that in the month of September there was an increased number of trades. This increase was up to two-fold, but did not generate higher profits. When using the binary options trades in September with all selected EMA indicators would be lost. The month of September can also be described as the lossiest month. The increase in the number of transactions has not been confirmed either in January. Among the most profitable months there were October, February and March. This clearly shows the use of the results in practice economics. 
Table 2 Testing of EMA in Different Months

\begin{tabular}{|c|c|c|c|c|c|c|c|c|c|c|c|}
\hline & & June & July & August & September & October & November & December & January & February & March \\
\hline \multirow{3}{*}{ 9-day EMA } & Signals & 1209,00 & 1497,00 & 1240,00 & 2357,00 & 1356,00 & 1301,00 & 1278,00 & 1284,00 & 1258,00 & 1456,00 \\
\hline & $\begin{array}{l}\text { Received } \\
\text { Signals }\end{array}$ & 913,00 & 1142,00 & 960,00 & 1011,00 & 1067,00 & 1007,00 & 987,00 & 988,00 & 992,00 & 1131,00 \\
\hline & Percentage & $75,52 \%$ & $76,29 \%$ & $77,42 \%$ & $42,89 \%$ & $78,69 \%$ & $77,40 \%$ & $77,23 \%$ & $76,95 \%$ & $78,86 \%$ & $77,68 \%$ \\
\hline \multirow{3}{*}{ 10-day EMA } & $\begin{array}{c}\text { Number of } \\
\text { Signals }\end{array}$ & 1139,00 & 1417,00 & 1164,00 & 2235,00 & 1282,00 & 1251,00 & 1208,00 & 1218,00 & 1198,00 & 1390,00 \\
\hline & $\begin{array}{l}\text { Received } \\
\text { Signals }\end{array}$ & 871,00 & 1094,00 & 909,00 & 965,00 & 1014,00 & 974,00 & 930,00 & 941,00 & 943,00 & 1094,00 \\
\hline & Percentage & $76,47 \%$ & $77,21 \%$ & $78,09 \%$ & $43,18 \%$ & $79,10 \%$ & $77,86 \%$ & $76,99 \%$ & $77,26 \%$ & $78,71 \%$ & $78,71 \%$ \\
\hline \multirow{3}{*}{ 12-day EMA } & $\begin{array}{c}\text { Number of } \\
\text { Signals }\end{array}$ & 1027,00 & 1305,00 & 1084,00 & 2025,00 & 1200,00 & 1143,00 & 1120,00 & 1112,00 & 1066,00 & 1272,00 \\
\hline & $\begin{array}{l}\text { Received } \\
\text { Signals }\end{array}$ & 786,00 & 1008,00 & 850,00 & 860,00 & 962,00 & 900,00 & 861,00 & 870,00 & 842,00 & 1015,00 \\
\hline & Percentage & $76,53 \%$ & $77,24 \%$ & $78,41 \%$ & $42,47 \%$ & $80,17 \%$ & $78,74 \%$ & $76,88 \%$ & $78,24 \%$ & $78,99 \%$ & $79,80 \%$ \\
\hline \multirow{3}{*}{ 26-day EMA } & $\begin{array}{c}\text { Number of } \\
\text { Signals }\end{array}$ & 731,00 & 829,00 & 748,00 & 1327,00 & 784,00 & 807,00 & 750,00 & 726,00 & 706,00 & 848,00 \\
\hline & $\begin{array}{l}\text { Received } \\
\text { Signals }\end{array}$ & 562,00 & 649,00 & 581,00 & 575,00 & 627,00 & 642,00 & 599,00 & 561,00 & 575,00 & 678,00 \\
\hline & Percentage & $76,88 \%$ & $78,29 \%$ & $77,67 \%$ & $43,33 \%$ & $79,97 \%$ & $79,55 \%$ & $79,87 \%$ & $77,27 \%$ & $81,44 \%$ & $79,95 \%$ \\
\hline
\end{tabular}

(Source: Author)

\section{DISCUSSION AND CONCLUSION}

The results of this work show that the length of the time frame is very important when deciding about the indicator, which will be used for technical analysis. The analysis clearly demonstrates the fact that the forex shops with EUR / USD currency pair is preferable EMA with higher timeframe. Differences in generated profitable signals were very small and percentage differences were in tenths of a percent, however the effect was evident. Further the increase in trading signals has been proved in the month of September. This increase, however, did not offer a higher profit strategy. The month of September can be described as the most loss month of the period under review. In the month of January, there was not demonstrated a greater activity in signal generation, as well as there was not a higher profitability in this period. Among the most profitable months there can be included October, February and March.

The subject of further testing could be other strategies based on averages, for example, crossing of moving averages, or sequence of moving averages, or a combination of indicators based on averages with others, for example oscillators and torque indicators, volatility indicators, or indicators of support and resistance. Alternatively, other currency pairs, commodities, indices and stocks might be subjected to further exploration. It could also be an interesting moment to examine profitability of individual strategies over the years of formation when it is assumed that at the time the indicator gave a higher percentage of profitable signals.

\section{REFERENCES}

Achelis, S. B. (2001). Technical analysis from A to Z. McGraw Hill New York.

Abbasi, E., \& Abouec, A. (2008). Stock price forecast by using neuro-fuzzy inference system. In Proceedings of the world academy of science, engineering and technology: 36 (pp. 320-323).

Appel, G. (2005). Technical analysis: power tools for active investors. FT Press.

Bollinger, John. (1992) Using Bollinger bands. Stocks \& Commodities, 10.2: 47-51.

Colby, R. W., \& Meyers, T. A. (1988). The encyclopedia of technical market indicators. Irwin New York. 
da Costa, T. R. C. C., Nazário, R. T., Bergo, G. S. Z., Sobreiro, V. A., \& Kimura, H. (2015). Trading system based on the use of technical analysis: A computational experiment. Journal of Behavioral and Experimental Finance, 6, 42-55.

Chavarnakul, T., \& Enke, D. (2009). A hybrid stock trading system for intelligent technical analysis-based equivolume charting. Neurocomputing, 72 (16), 3517-3528.

Cheung, W. M., \& Kaymak, U. (2007). A fuzzy logic based trading system. In Proceedings of the third European symposium on nature inspired smart information systems, 07. St. Julians, Malta.

Chourmouziadis, K., \& Chatzoglou, P. D. (2015). An intelligent short term stock trading fuzzy system for assisting investors in portfolio management. Expert Systems with Applications .doi: 10.1016/j.eswa.2015.07.063.

Jaworski, A. (2006) CBOT Launches Binary Options. Securities Industry News. 18, 27, 11, 24.7., 2006. ISSN: 10896333.

Jurník, D. (2013) Co jsou to binární opce a jak to funguje. http://www.binarni-opce.com/manualbinarnich-opci/co-jsou-to-binarni-opce-a-jak-to-funguje Consulted: 8. 42013

Kaufman, P.J., (1987). The New Commodity Trading Systems and Methods. New York: John Wiley and Sons. ISBN 978-1-118-0-4356-1

Kim, Hong-Joong; Moon, Kyoung-Sook. (2011) Variable time-stepping hybrid finite difference methods for pricing binary options. Bulletin of the Korean Mathematical Society. Volume 48, Issue 2, 2011, pp.413-426, Publisher : The Korean Mathematical Society

Lane, G. C. (1984). Lane's stochastic. Technical Analysis of Stocks and Commodities, 2 (3), 80.

Lee, K., \& Jo, G. (1999). Expert system for predicting stock market timing using a can-dlestick chart. Expert Systems with Applications, 16 (4), 357-364.

Miyake, M, Inoue, H, Shi, J, \& Shimokawa, (2014), 'A Binary Option Pricing Based on Fuzziness', International Journal Of Information Technology \& Decision Making, 13, 6, pp. 1211-1227, Business Source Premier, EBSCOhost, viewed 26. 4. 2016.

Rick Thachuk (2010) Binary options - the next big retail investing boom? FOW [online]. 2010. ISSN 14629658.

Thavaneswarana, A. Appadoob, S.S. Frank, J (2013) Binary option pricing using fuzzy numbers. Applied Mathematics Letters, Volume 26, Issue 1, January 2013, Pages 65-72

Wilder, J. W. (1978). New concepts in technical trading systems. Trend Research Greens-boro, NC. Zmeskal, Z. (2012) Generalized soft binomial American real option model (fuzzy-stochastic approach). European Journal of Operational Research, 207, pp. 1096-1103 